\title{
CitSci.org \& PPSR Core: Sharing biodiversity observations across platforms
}

\author{
Brandon Budnicki $\ddagger^{\ddagger}$ Gregory John Newman ${ }^{\ddagger}$ \\ ‡ Colorado State University, Fort Collins, United States of America
}

Corresponding author: Brandon Budnicki (budnicki@colostate.edu), Gregory John Newman (gregory.newman@ colostate.edu)

Received: 23 Sep 2021 | Published: 23 Sep 2021

Citation: Budnicki B, Newman GJ (2021) CitSci.org \& PPSR Core: Sharing biodiversity observations across platforms. Biodiversity Information Science and Standards 5: e75666. https://doi.org/10.3897/biss.5.75666

\begin{abstract}
CitSci.org is a global citizen science software platform and support organization housed at Colorado State University. The mission of CitSci is to help people do high quality citizen science by amplifying impacts and outcomes. This platform hosts over one thousand projects and a diverse volunteer base that has amassed over one million observations of the natural world, focused on biodiversity and ecosystem sustainability. It is a custom platform built using open source components including: PostgreSQL, Symfony, Vue.js, with React Native for the mobile apps. CitSci sets itself apart from other Citizen Science platforms through the flexibility in the types of projects it supports rather than having a singular focus. This flexibility allows projects to define their own datasheets and methodologies.
\end{abstract}

The diversity of programs we host motivated us to take a founding role in the design of the PPSR Core, a set of global, transdisciplinary data and metadata standards for use in Public Participation in Scientific Research (Citizen Science) projects. Through an international partnership between the Citizen Science Association, European Citizen Science Association, and Australian Citizen Science Association, the PPSR team and associated standards enable interoperability of citizen science projects, datasets, and observations. 
Here we share our experience over the past 10+ years of supporting biodiversity research both as developers of the CitSci.org platform and as stewards of, and contributors to, the PPSR Core standard. Specifically, we share details about:

1. the origin, development, and informatics infrastructure for CitSci

2. our support for biodiversity projects such as population and community surveys

3. our experiences in platform interoperability through PPSR Core working with the Zo oniverse, SciStarter, and CyberTracker

4. data quality

5. data sharing goals and use cases.

We conclude by sharing overall successes, limitations, and recommendations as they pertain to trust and rigor in citizen science data sharing and interoperability. As the scientific community moves forward, we show that Citizen Science is a key tool to enabling a systems-based approach to ecosystem problems.

\section{Keywords}

citizen science, biodiversity, data quality, metadata model, data standard, community science, crowd science, crowd-sourced science, civic science

\section{Presenting author}

Brandon Budnicki

\section{Presented at}

TDWG 2021 